\title{
Fuzzy-IP Controller for Voltage Regulation in a Stand-Alone Microgrid System
}

\author{
Seno D. Panjaitan ${ }^{1}$, Bomo W. Sanjaya ${ }^{2}$, Rudi Kurnianto ${ }^{3}$
}

\begin{abstract}
This paper presents a method that combines fuzzy inference system and IntegralProportional named Fuzzy-IP controller to regulate an independent microgrid voltage with a distributed energy resource unit. The unit employed photovoltaic $(P V)$ array with DC voltage converted to three-phase AC voltage. The control design was carried out through modeling and simulation using Matlab software environment. Transfer function with the $2 \times 2$ structure using system identification has estimated the non-linear plant model. Two controllers transformed the a$b-c$ to the $d-q$ axis coordinates of voltage to simplify linear control design. An oscillator is applied to set frequency according to the recommendation. The results show that the compensated casestudy system using Fuzzy-IP with disturbance tracked the setpoint excellently and it regulated the voltage properly including frequency control using internal oscillator. The paper presents performance superiority of the proposed method over PI control by comparing the transient response, the mean squared error, and the root mean squared error. Copyright (C) 2018 The Authors.
\end{abstract}

Published by Praise Worthy Prize S.r.l.. This article is open access published under the CC BY-NC-ND license (http://creativecommons.org/licenses/by-nc-nd/3.0/).

Keywords: Smart Grid, Microgrid, Energy Control, Distributed Generator, Distributed Energy Resource

\section{Nomenclature}

$V_{a b c}$

$r_{1} / r_{2}$

$y_{1} / y_{2}$

$u_{1} / u_{2}$

$D_{1} / D_{2}$

$G p$

$G p_{11}$

$G p_{12}$

$G p_{21}$

$G p_{22}$

$e$

de

$X_{i, 1}$

$X_{i, 2}$

$X_{i, 3}$

$\mu_{A}(z)$

$z_{C O A}$ and $u_{1}$ and $u_{2}$ rules number the rules number the rules number

(MF) a fuzzy set A

\section{Three-phase Load Voltage}

Reference of $d$-axis / $q$-axis coordinates

Output of $d$-axis / $q$-axis coordinates

Input related to $d$-axis / $q$-axis coordinates

Disturbance to $d$-axis / $y$-axis coordinates

Transfer function of the entire plant

Transfer function between $y_{1}$ and $u_{1}$

Transfer function of the coupling between $y_{2}$

Transfer function of the coupling between $y_{1}$

Transfer function between $y_{2}$ and $u_{2}$

Error which is the difference between reference input and actual output, e.g. $e_{1}$ (for $d$-axis $)=y_{1}-r_{1}, e_{2}$ (for $q$-axis $)=y_{2}-r_{2}$

Differential error or error change

fuzzy sets of $e$ (input variable) where $i$ is the

fuzzy sets of $d e$ (input variable), where $i$ is

Fuzzy set of $K_{K i}$ (output variable), where $i$ is

Aggregated output Membership Function

Aggregation result on fuzzy inference system based on method Centroid of Area
$K_{i} \quad$ Integral gain of PI controller where $K i_{\min }$ and $K i_{\max }$ are respectively the minimum and maximum value of $K_{i}$

$K_{K i} \quad$ Coefficient generated by the fuzzy system for $K i_{\text {max }}-K i_{\text {min }}$

$K p \quad$ Proportional gain of PI Controller

$G c(s) \quad$ Transfer function of the controller

pu Per unit dimensionless value (maximum 1)

\section{Introduction}

Electrical engineering capacity from renewable sources is increasing steadily and it is bringing a new paradigm of a distribution system that faces new challenges in adopting new control mechanism and framework to integrate many kinds of available energy sources with different characteristics. The renewable sources offer the potential of a sustainable and an environmental-friendly power generation, but the technologies still present challenges due to their intermittent characteristics. Efforts to apply control engineering in the conversion, distribution process and conservation have been attracting much attention to recent researches due to the present and uprising energy and environmental problems. The new topology and design of generation and distribution systems from renewable sources develop continuously. It is essential to understand the distinctive characteristics of each element of the system and the interaction between them, in order 
to successfully incorporate and control a variety of plants [1]-[27]. Furthermore, microgrid systems have an important role in involving multiple energy sources. A microgrid is a power grid in a small size with two operation modes: independent (stand-alone) and gridconnected. It allows the implementation in wide range area even in the remote one, which represents an issue in developing countries. By implementing the microgrid concept, electrical supply and demand (grid-connected or stand-alone mode) can be flexible. Nowadays, control strategies in microgrid systems are still an open issue in accordance to power-sharing, stability, frequency, voltage, active, reactive power, synchronization, as well as connecting/ disconnecting detection and system recovery [1].

The microgrid system becomes more significantly complicated in facing some current technical and other challenges. Therefore, the use of the utility, nonrenewable and renewable energy including the storage needs appropriate control techniques to be applied in a hybrid and a smart way to get the best performance. Control engineering has an important role to enhance the performance. Microgrid generally consists of three levels [1]-[2]. The primary level controls the energy sources and their interfaces to operate in a normal operation based on the local requirements that generally need no communication infrastructure. The secondary level mainly controls power quality once the system has several and different energy sources. The tertiary level relates to power interchange between microgrids and the utility.

The microgrid controller must secure the operation modes either grid-connected or stand-alone where the success of disconnection and reconnection processes mainly depend on microgrid control. It must guarantee the seamlessly processes in the system working in the specified operating points. The stand-alone operation mode requires an accurate load sharing mechanism since it must control frequency and voltage of the system independently. The power mismatch that may happen in the load sharing can cause high circulating current. The stand-alone electrical source and the dynamics of electrical load can reduce power quality due to the use of electrical equipment [3]-[4]. A converter can operate as a master unit for voltage regulation [5], and an internal oscillator can control the frequency. Some techniques in powers sharing control are presented in [6]-[10].

In the primary control level, the voltage control is quite challenging due to load dynamics and power transients. The transients may arise as a result of direct lightning strikes or inductions, switching loads on or off, switching of the power line or capacitor banks, and interruption of fault currents [5]. Some examples of the proposed techniques to solve these challenges are sliding mode [11], $\mu$-synthesis [12], robust [13]-[15], robust servomechanism [16], and convex optimization [17]. However, most of these control methods are based on a mathematical model developed from the electrical components values such as resistance, inductance, and capacitance. Sometimes it is not easy to get the exact values for those components mainly in the real systems. Moreover, some of the presented systems are based on the fixed DC source and they are focused on the dynamic in the inverter to regulate the voltage. The control system design should consider the intermittent character of the DC source. Proportional-integral (PI) control scheme is commonly used for voltage regulation in power systems, but it has difficulties with the sensitivity of the various values of the parameters and also with non-linearity of the system. Another approach using Fuzzy adaptive [18] presents its superiority by comparing to the proportionalderivate control scheme. The fuzzy logic approach is also proposed in [19] using fix DC source. However, the system should be tested by the dynamics of DC source and disturbances regarding the load uncertainties to consider carefully to the real case in power systems especially microgrid.

This paper uses system identification to get the mathematical models (i.e., transfer functions) of the plant with minimum system order. These models are linear and they will reduce the burden with the unknown parameter values of the system such as resistance, inductance, and capacitance. A method, named Fuzzy-IP, is developed in this paper to regulate voltage magnitude in an independent microgrid. In this scheme, fuzzy inference system (FIS) is used to dynamically set the integral parameter that has integral-proportional (I-P) control scheme. The proportional gain is not connected to the error but it is directly connected to the feedback signal from the output to reduce the impact of system dynamics. Meanwhile, the dynamics of the error $(e)$ and differential error $(d e)$ are set to be the FIS inputs. The output of the FIS is the $K_{K i}$ value, which is a dynamic integral value to compensate the system with the better tracking capability. The microgrid in the presented case has a DC source from a photovoltaic system and then it is converted to three-phase AC voltage. A phase-locked loop (PLL) controls the frequency to fulfill the requirement.

\section{Research Method}

The controller design goal is to have regulated voltage and frequency according to the setpoint in the microgrid system energized by the DC source by involving perturbation in the PV system and disturbances. The modeling and simulation of the system and its control have used Matlab software, especially Simulink and SimPowerSystems.

Fig. 1 displays a high-level semantic of the microgrid with one DER unit. In this system, solar energy provides electricity for $\mathrm{AC}$ microgrid after voltage conversion using a voltage-sourced converter (VSC) or also called inverter. The three-phase voltage of the load $\left(V_{a b c}\right)$ will be controlled to have robust stability and small steady state error compared to the setpoint. The controller will face two uncertainties, which are the intermittent character of the photovoltaic (PV) source as the DC 
voltage input due to various temperature and the solar irradiance and disturbances that mainly due to the load dynamics that are affected by connection and disconnection of the load(s). Point common coupling (PCC) connects or disconnects microgrid to the leading network, where the exchange power becomes possible [18]. This point also connects the grid to the load. Therefore, $V_{a b c}$ is measured at PCC. In stand-alone mode, PCC disconnects from the primary network, so the microgrid works independently using the available DER. It means that the voltage and frequency control are switched from the centralized scheme of the main grid to the decentralized one in which microgrid has to own its independent authority. The control strategy will be challenging due to the power difference between DER and the loads caused by inappropriate control strategy at microgrid level. Therefore, the local controller in microgrid level must seamlessly capable to regulate the voltage and the frequency, especially in transition from connected grid-connected to stand-alone mode.

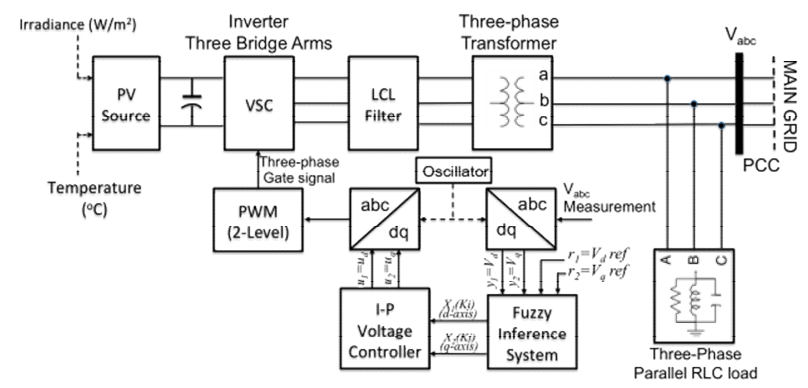

Fig. 1. High-level model semantic of the Stand-alone Microgrid System

Furthermore, a 2-level power width modulation (PWM) produces a gate signal for inverter after receiving a three-phase signal in $a-b-c$ axis coordinates from the controller. This transformation is required since the system dynamics using $a-b-c$ axis coordinates are nonlinear, so it will need a great effort to design a simple linear controller if there is no estimation. Therefore, the actual output $\left(V_{a b c}\right)$ which has $a-b-c$ axis coordinates is transformed to $d-q$ axis coordinates, in order to build the system dynamics model with a linear approximation. By doing this, the design and analysis of the linear controller are much more straightforward since it can use linear methods that are available in many design tools. This transformation, as an example, has been successfully applied to control voltage and current of a three-phase motor using anti-windup compensator [20]. The $d-q$ axis coordinates of the actual output are then considered as two feedback signals and compared to the $d$ and $q$ references. The errors are then compensated by the controller and after transforming the signal back to the $a$ $b-c$ axis coordinates. This signal controls the PWM reference input and subsequently becomes a gate signal for the VSC. Regarding the frequency, an internal oscillator (phase-locked loop, PLL) controls the frequency according to the standard. In this case, it is 50 $\mathrm{Hz}$.
The PV source in this paper has a maximum DC voltage magnitude at $1,500 \mathrm{~V}(1 \mathrm{pu})$. An inverter, with three bridge arms controlled by three-phase gate signal produced by PWM as a subsequent process from the controller, will convert the DC voltage to AC. The output of the inverter is a three-phase bipolar square signal. This signal will be filtered by an LCL filter to reduce the harmonics produced by the inverter and smooth the waveform. Then, a step-up transformer will increase the voltage magnitude to track the voltage set-point magnitude for the three-phase local load. The microgrid is connected to $20 \mathrm{~kW}$ parallel RLC load at the beginning. Then at $2 \mathrm{~s}$, connecting additional $10 \mathrm{~kW}$ in parallel increases the total RLC load value. In this load change, the controller must compensate the system to the steady state.

In this paper, the plant transfer functions are estimated using system identification. By using input (i.e., square signal) and output data of uncontrolled plant with perturbation from the various DC voltage from PV source, the transfer functions estimation using Matlab and the primary parameter is mean squared error (MSE). Numerator and denumerator can be selected considering those three parameters. Afterward, the controllers designed in this paper combine fuzzy inference system (FIS) and Proportional-Integral (PI) scheme. The $e$ and $d e$ will be fuzzified, aggregated and defuzzified by the FIS and they generate $K_{K i}$ added to the calculation of integral parameter $K i$. This process runs automatically depending upon the $e$ and $d e$ magnitudes.

Fig. 2 shows the diagram that has a combination of FIS and PI. The combination means that the output of FIS sets the coefficient parameters of the PI. The two references are $r_{1}$ and $r_{2}$ respectively for $d$-axis and $q$-axis. Assuming that the microgrid has a balanced condition, $r_{1}$ represents PCC voltage magnitude setpoint regarding the active power, while $r_{2}$ that represents the voltage regarding the reactive power that always has a zero value. In this case, $r_{1}$ is a step function with magnitude 1 per unit (pu) at the beginning, reduced to $0.8 \mathrm{pu}$ at $0.3 \mathrm{~s}$, where pu is a dimensionless ratio based on its original value. For the voltage, $1 \mathrm{pu}$ is representing $13.8 \mathrm{kV}$. The FIS combined with PI controller produces two outputs namely $u_{1}$ and $u_{2}$ that will be the inputs for the plant $\left(G_{p}\right)$. In Fig. 1, the value of $u_{1}$ and $u_{2}$ that is in $d-q$ axis coordinates will be transformed to $a-b-c$ as the representation of the three-phase voltage lines. This signal is a reference for PWM to set a three-phase signal to the inverter gate. $G_{p}$ is composed of four transfer functions with $2 \times 2$ structure namely $G p_{11}, G p_{12}, G p_{21}$, and $G p_{22}$. $G p$ represents the mathematical model estimation for the microgrid system in Fig. 1 consisting in $d q-a b c$ transformation, DER (PV-source and VSC), LCL filter, three-phase step-up transformer, three-phase parallel RLC load(s), three-phase PCC voltage $\left(V_{a b c}\right)$, and $a b c-d q$ transformation.

Fig. 3 shows FIS design for $d$-axis controller that uses the Mamdani method, in which the system has two variables for inputs and one output, which are similar for 
both controllers. The decomposition of the input variables $e$ representing $\mathrm{e}_{1}$ and $\mathrm{e}_{2}$, and $d e\left(d e_{1}\right.$ and $\left.d e_{2}\right)$ are Negative $(\mathrm{N})$, Zero $(\mathrm{Z})$, and Positive $(\mathrm{P})$. The output variable namely $K_{K i}$ is an additional amount to the minimum value of integral control gain $(K i)$ at $d$-axis and $q$-axis controller. This fuzzy variable is decomposed into Small (S), Medium (M), and Big (B), respectively.

Fig. 3 shows that the membership functions (MFs) represent the fuzzy sets. The i-th fuzzy rule in the rule base of FIS for $d$-axis and $q$-axis controller is generally designated by:

Rule $i$ : IF $e$ is $X_{\mathrm{i}, 1}$ AND de is $X_{\mathrm{i}, 2}$ THEN $K_{K i}$ is $X_{\mathrm{i}, 3}, i=1$, $\ldots, 9$.

where $i$ is the rules number, $X_{\mathrm{i}, 1}, X_{\mathrm{i}, 2}$, and $X_{\mathrm{i}, 3}$ are respectively the fuzzy sets defining the linguistics terms of the input variables $e\left(e_{1}\right.$ or $\left.e_{2}\right)$, de $\left(d e_{1}\right.$ or $\left.d e_{2}\right)$, and the output variable $K_{K i}\left(K_{K i 1}\right.$ or $\left.K_{K i 2}\right)$. In this research, there are nine rules set for the FIS listed in Table I.

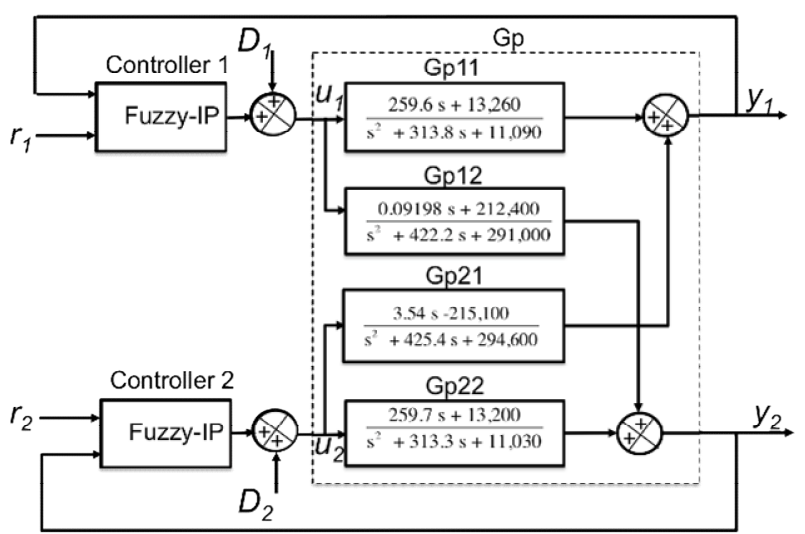

Fig. 2. Block diagram of the controlled system

Mamdani has a simple structure with a min-max operation and commonly used in many applications. This method is based on the fuzzy theory in [21] which was then developed to be a control combination [22]. The centroid of area (COA) defuzzification method is applied in this paper to get outputs $\left(K_{K i 1}\right.$ and $\left.K_{K i 2}\right)$ of the FIS. The outputs are obtained by taking the fuzzy area center point, generally formulated in (1):

$$
z_{C O A}=\frac{\int_{z} \mu_{A}(z) z d z}{\int_{z} \mu_{A}(z) d z}
$$

where $A$ is a fuzzy set of a universe of discourse $Z$, $\mu_{A}(z)$ is the aggregated output MF. Figs. 4 show the surface of a relation between $e$, $d e$, and $K_{K i}$. $K_{K i 1}$ and $K_{K i 2}$ represent the coefficient of $K i$ with variation from 0 to 1 , and each of them in the FIS will be connected to an integral gain $(K i) . K i$ applies first Zieger-Nichols method [23] to determine its values. The difference with conventional PI control design is that $K i$ can vary due to the coefficient $K_{K i}$ where it is a fixed value in the original method. The FIS will accelerate the response during the significant error to reach a steady state quickly, and then slightly response after reaching that state.

The calculation of $K i$ values is shown in Equation (2):

$$
K i=K i_{\text {min }}+K_{K i}\left(K i_{\text {max }}-K i_{\text {min }}\right)
$$

The PI controller has the following ideal form:

$$
G c(s)=K p+\left(1+K i \frac{1}{s}\right)
$$

TABLE I

LIST OF FUZZY RULES FOR $K_{K i 1}$ AND $K_{K i 2}$

\begin{tabular}{cccc}
\hline $\boldsymbol{e}$ & $\mathbf{d e}$ & $\mathbf{Z}$ & $\mathbf{N}$ \\
\hline $\mathrm{P}$ & $\mathrm{B}$ & $\mathrm{M}$ & $\mathrm{S}$ \\
$\mathrm{Z}$ & $\mathrm{S}$ & $\mathrm{S}$ & $\mathrm{S}$ \\
$\mathrm{N}$ & $\mathrm{S}$ & $\mathrm{M}$ & $\mathrm{B}$ \\
\hline
\end{tabular}
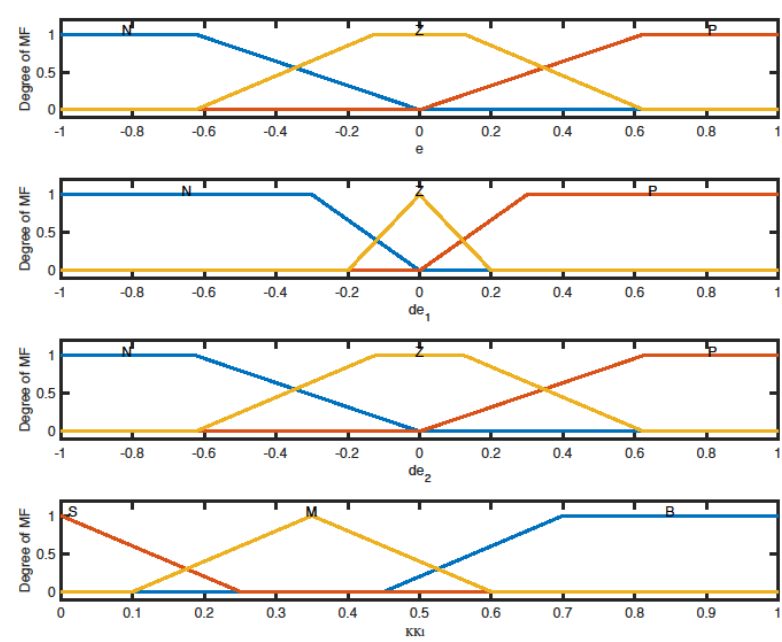

Fig. 3. MFs of inputs ( $e$ and $d e$ ) and output $K_{K i}$

\section{Results and Analysis}

This section will present the superiority of the proposed controller named Fuzzy-IP over the PI control scheme to regulate the microgrid voltage during the disturbances. Some simulation results show both $d-q$ and $a-b-c$ (three-phase) axis coordinates of voltage, as well as their power and current waveforms.

\section{III.1. DER Characteristics without Controller}

The DER unit presented in this paper is a PV-array source with characteristics Current-Voltage (I-V) and Power-Voltage (P-V). The PV-array consists of PV modules type SunPower-SPR-305-WHT with 24 seriesconnected modules per string and 150 parallel strings. Each module has $96 \mathrm{PV}$ cells with $64.2 \mathrm{~V}$ open circuit voltage, 5.96 A short-circuit current, and $54.7 \mathrm{~V}$ voltage at the maximum power point.

Fig. 5(a) describes the characteristics of I-V and P-V and the various irradiation values. The current and the 
power in a PV-array reach the maximum values when the voltage is about $1,3 \mathrm{kV}$.

Fig. 5(b) shows the characteristics of the PV source for the uncompensated system regarding the PV voltage $\left(v_{P V}\right)$, the PV current $\left(i_{P V}\right)$, the diode current $\left(i_{\text {diode }}\right)$, the irradiation (irr) and the temperature $(T)$. It confirms that solar irradiation and temperature influence the PV voltage and PV current values. At $25^{\circ} \mathrm{C}$, the PV produces electricity proportionally with the irradiation, but when the temperature increases to $75^{\circ} \mathrm{C}$, the electric generation decreases slightly. These characteristics reveal the input description to the VSC that converts the voltage to the three-phase type with $a-b-c$ axis coordinates.

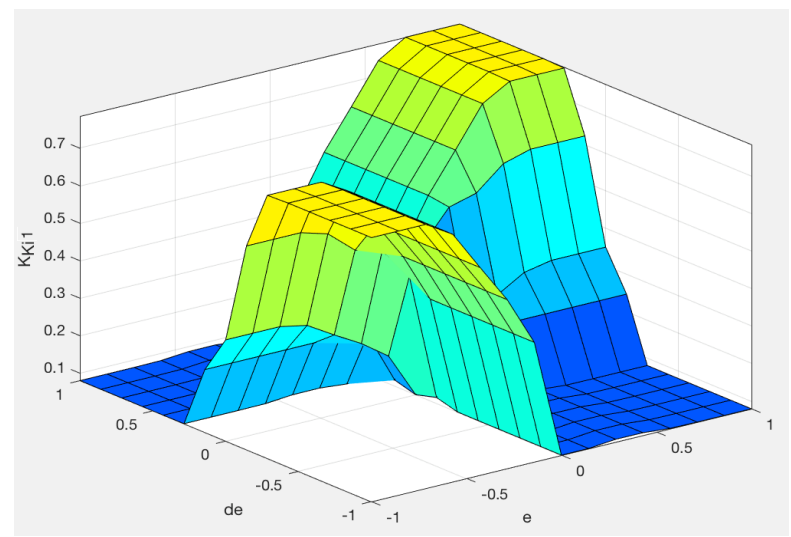

(a) d-axis coordinate

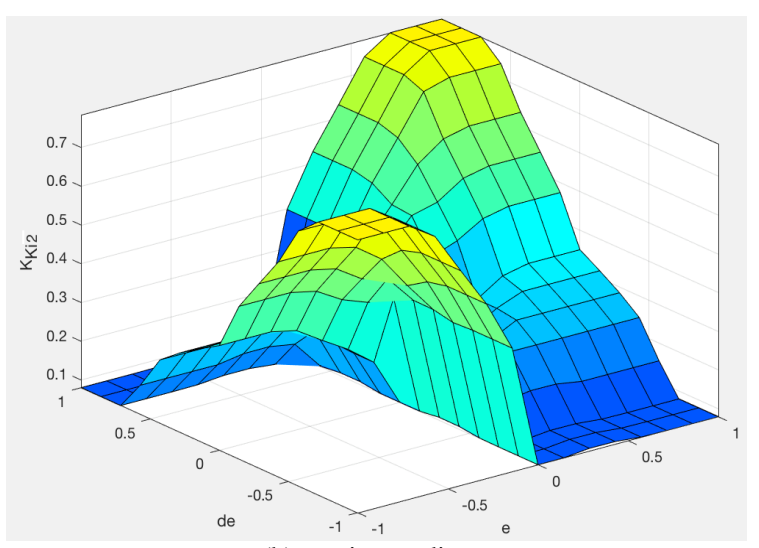

(b) $q$-axis coordinate

Figs. 4. Surface view of designed rules for $d-q$ axis coordinates

\section{III.2. Uncompensated Microgrid System Performance}

The performance of the uncompensated or uncontrolled system response to the unit-step input in Fig. 6 shows that it lacks the capability of tracking the setpoint since the voltage is influenced by the intermittent character of the PV source and load uncertainties. The $d$ voltage value $\left(y_{1}\right)$ reveals a more substantial error compared to the reference, which is a unit-step $\left(u_{1}\right)$. Meanwhile, the $q$-axis voltage $\left(y_{2}\right)$ is being a negation of the $q$-axis voltage. Its input $\left(u_{2}\right)$ is zero while another input from the $d$-axis $\left(y_{1}\right)$ gives a coupling effect with a negative number to the $q$-axis due to the $2 \times 2$ multipleinput-multiple-output (MIMO) structure of the system. It makes the $q$-axis voltage value affecting the $d$-axis coordinates of voltage. Then, the $d-q$ axis coordinates that represent $V_{a b c}$ magnitude confirm that the system needs to be controlled to improve its voltage regulation. The system has to face the disturbances that are generated by the load uncertainties or others. The disturbances can affect both active and reactive parts of the power quality.
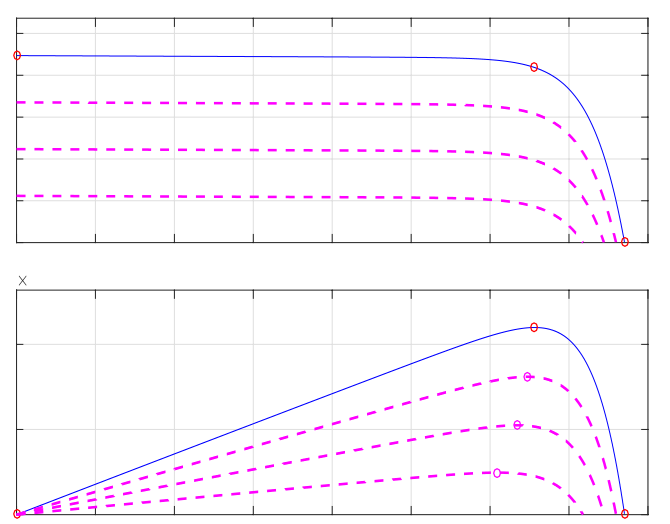

(a)

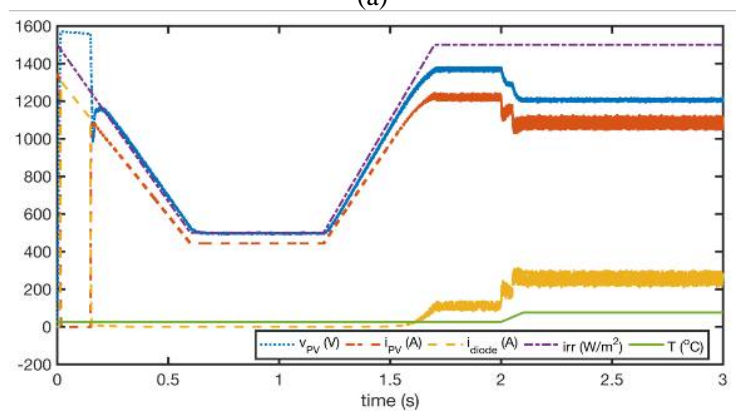

(b)

Figs. 5. Characteristics of the PV: (a) I-V and P-V of the PV-array, (b) PV-Source

\section{III.3. Compensated Microgrid System Performance}

The system involves the disturbances at $0.2 \mathrm{~s}$ for both d- and q- axis coordinates as shown in Figs. 7. These disturbances are represented respectively as D1 and D2 in Fig. 2. In the simulation, the voltage disturbances will be multiplied by $20 \%$ as the maximum value. Therefore, in total, the disturbances are in range $0-0.2 \mathrm{pu}$. The controller has to face the disturbances and it has to keep the tracking capability to have less error, especially in a steady state. The responses in $\mathrm{d}-\mathrm{q}$ axis coordinates will show the performance of the compensated system.

Fig. 8 shows the tracking capability between Fuzzy-IP and PI method to control the system under disturbances. In this case, $r_{1}$ ( $d$-axis setpoint) is a unit-step reference and $r_{2}$ ( $q$-axis setpoint) is a zero value reference while $y_{1}$ and $y_{2}$ are the output signals respectively. The unit-step responses of d-q axis show that Fuzzy-IP is superior to PI, based on transient characteristics, MSE and root mean squared error (RMSE). As the representation of $V_{a b c}, y_{d q}$ characteristics using Fuzzy-IP controller are the following: $0.008 \mathrm{~s}$ rise time, $5 \%$ maximum overshoot, and 0.030 settling time, while using PI rise time and 
settling time are respectively $0.029 \mathrm{~s}$ and $0.045 \mathrm{~s}$ without overshoot. The transient response shows that system compensates using Fuzzy-IP can react faster. Furthermore, MSE and RMSE using Fuzzy-IP are also better than PI control as listed in Table II.

TABLE II

MSE AND RMSE VALUES: FUZZY-IP VS PI CONTROLLER

\begin{tabular}{cccccc}
\hline \hline \multicolumn{2}{c}{ Parameters } & \multicolumn{2}{c}{$\begin{array}{c}\text { Response with } \\
\text { Fuzzy-IP }\end{array}$} & \multicolumn{2}{c}{ PI Controller } \\
\hline Signal & Ref. & MSE & RMSE & MSE & RMSE \\
\hline $\mathrm{y}_{1}$ & $\mathrm{r}_{1}$ & 0.0014 & 0.0379 & 0.0017 & 0.0411 \\
$\mathrm{y}_{2}$ & $\mathrm{r}_{2}$ & 0.29932 & 0.0173 & 0.37001 & 0.0192 \\
$\mathrm{y}_{\mathrm{dq}}$ & $\mathrm{r}_{\mathrm{dq}}$ & 0.0013 & 0.0360 & 0.0015 & 0.0383 \\
\hline \hline
\end{tabular}

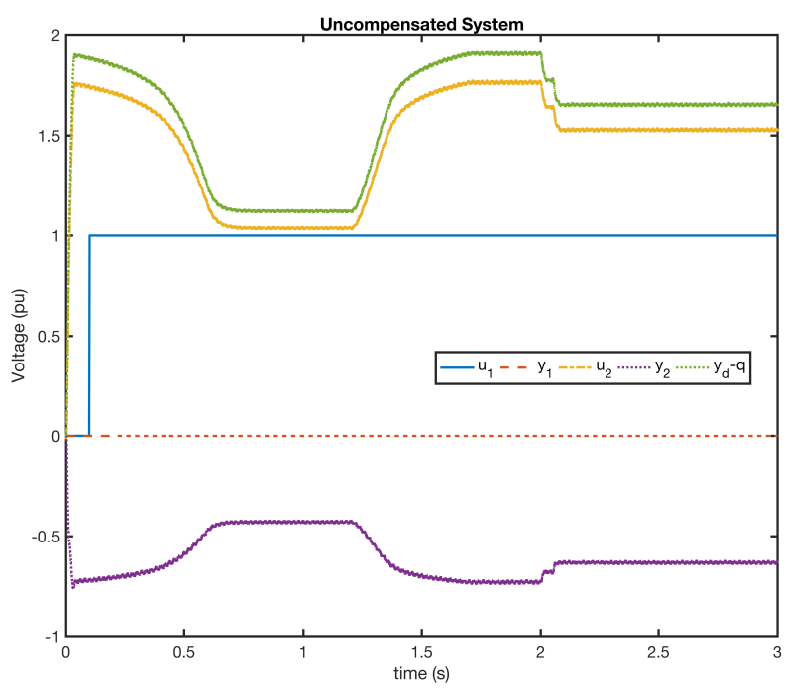

Fig. 6. Unit-step Response of the uncompensated Microgrid System

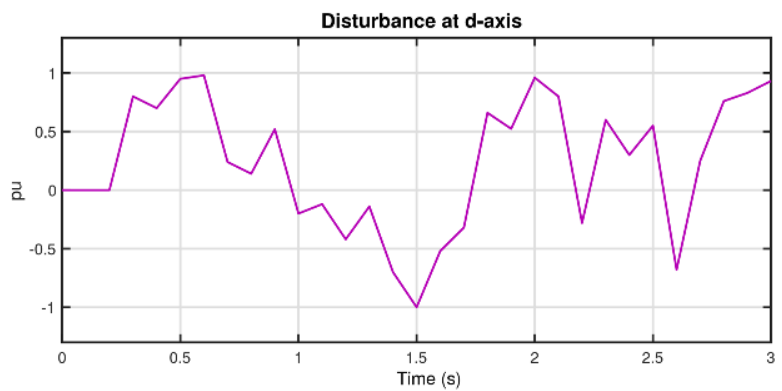

(a)

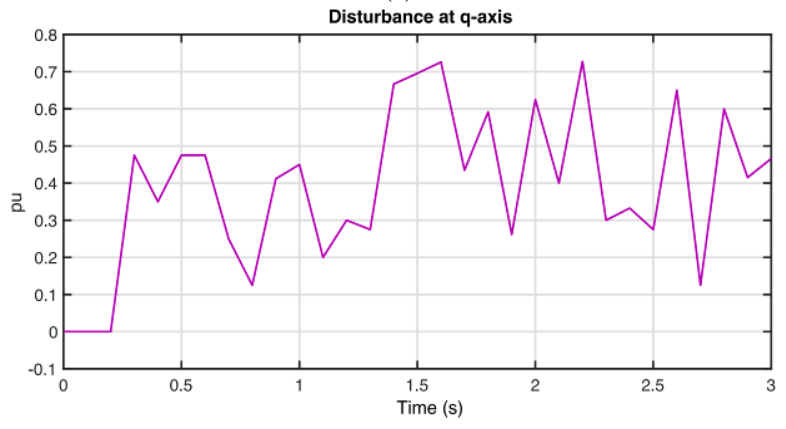

(b)

Figs. 7. Disturbance at the Control System Model: (a) $D_{1}$ and (b) $D_{2}$

Figs. 9 depict the three-phase signal representation that transformed from the $d-q$ axis coordinates. It confirms that the system has an excellent response according to the set point during the transient and disturbances either at active ( $d$-axis) or reactive ( $q$-axis) voltage.
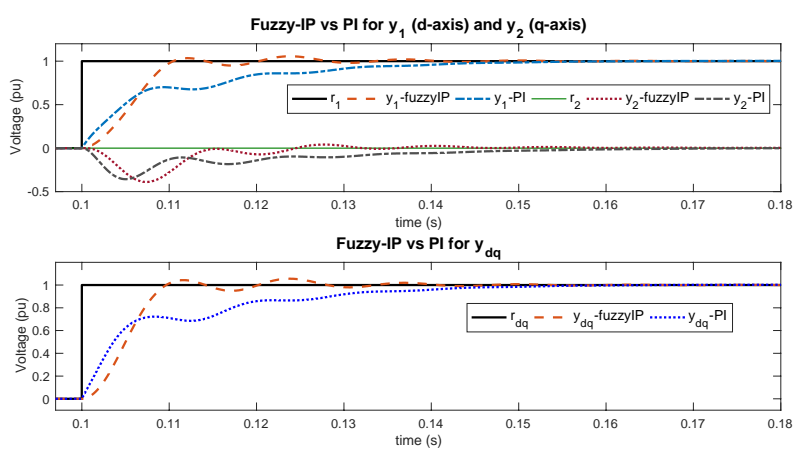

Fig. 8. The unit-step response of the compensated system: Fuzzy-IP vs. PI
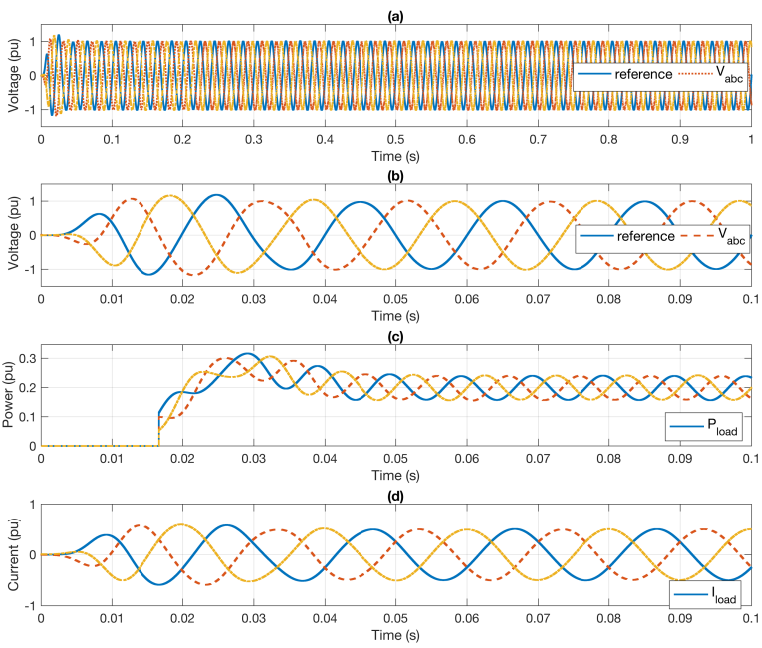

Figs. 9. Three-phase Signal Responses of the Compensated System using Fuzzy-IP Controller: (a) Voltage $\left(\mathrm{V}_{\mathrm{abc}}\right)$, (b) $\mathrm{V}_{\mathrm{abc}}$ at transition, (c) Power, (d) Current

\section{Conclusion}

The paper has elucidated the superiority of Fuzzy-IP controller to regulate voltage in a microgrid system during stand-alone mode. In this mode, a microgrid must control the voltage magnitude and frequency independently. The superiority of Fuzzy-IP control has been presented over the conventional voltage control method using PI. It combines fuzzy inference system to set the integral parameters, while the proportional gain is directly connected to the output instead of to the error like in PI. In the recent non-linear technique, the model used to have a complex mathematical and it needed great efforts to handle the dynamics of the system in the simulation. In this paper, transfer functions of the system were modeled using estimation from system identification technique to result in a linear plant model. It makes an effort to find the plant model easier. The $a b c$ $d q$ transformation or vice versa has emphasized the appeal of the method being used to ease linear control 
design from a non-linear plant. Based on the simulation results in Matlab environment, voltage control using Fuzzy-IP in a microgrid system with PV source as DER unit shows an excellent performance confirmed by the reference tracking and the system robustness. Meanwhile, the frequency set by the PLL presented a very less error regarding the standard (i.e., $50 \mathrm{~Hz}$ ). The future work will be to set the controller in a distributed way for the powersharing using the distribution and scheduling technique that presented in [24].

\section{Acknowledgements}

The authors would like to thank DRPM KemenristekDikti Indonesia that provides the grant through PKLN scheme, Universitas Tanjungpura, department of electrical engineering at the University of Leicester especially Professor Turner who helped to give some comments to improve the quality of this paper.

\section{References}

[1] H. Bevrani, M. Watanabe, Y. Mitani, Power system monitoring and control (John Wiley \& Sons, 2014).

[2] D.E. Olivares, A. Mehrizi-Sani, A.H. Etemadi, C.A. Cañizares, R. Iravani, M. Kazerani, A.H. Hajimiragha, O. Gomis-Bellmunt, M. Saeedifard, R. Palma-Behnke, G.A. Jiménez-Estévez, and N.D. Hatziargyriou, Trends in Microgrid Control, IEEE Transactions on Smart Grid, Vol. 5 (issue 4):1905-1919, July 2014.

[3] C. Sankaran, Power Quality (CRC Press, 2002).

[4] S. Chattopadhyay, M. Mitra, S. Sengupta, Electric Power Quality, (Springer Science+Business Media B.V., 2011).

[5] J.A.P. Lopes, C.L. Moreira, and A.G. Madureira, Defining control strategies for MicroGrids islanded operation, IEEE Transactions on Power Systems, Vol. 21 (issue 2): 916-924, May 2006.

[6] M.B. Delghavi, A. Yazdani, An Adaptive Feedforward Compensation for Stability Enhancement in Droop-Controlled Inverter-Based Microgrids, IEEE Transactions on Power Delivery, Vol. 26 (issue 3): 1764-1773, July 2011.

[7] P. Li, X. Wang, W. Lee, and D. Xu, Dynamic Power Conditioning Method of Microgrid Via Adaptive Inverse Control, IEEE Transactions on Power Systems, Vol. 30 (issue 2): 906-913, April 2015.

[8] M.J. Hossain, H.R. Pota, M.A. Mahmud, and M. Aldeen, Robust Control for Power Sharing in Microgrids With Low-Inertia Wind and PV Generators, IEEE Transactions on Sustainable Energy, Vol. 6 (issue 3): 1067-1077, July 2015.

[9] Q. Zhong, G. Weiss, Synchronverters: Inverters That Mimic Synchronous Generators, IEEE Transactions on Industrial Electronics, Vol. 58 (issue 4): 1259-1267, April 2011.

[10] Q. Zhong, G. Konstantopoulos, B. Ren, and M. Krstic, Improved Synchronverters with Bounded Frequency and Voltage for Smart Grid Integration, IEEE Transactions on Smart Grid, May 2017 [in press].

[11] M. Cucuzzella, G.P. Incremona, and A. Ferrara, Design of Robust Higher Order Sliding Mode Control for Microgrids, IEEE Journal on Emerging and Selected Topics in Circuits and Systems, Vol. 5 (issue 3 ): 393-401, September 2015.

[12] M. Babazadeh, H. Karimi, $\mu$-synthesis control for an islanded microgrid with structured uncertainties, Annual Conference of the IEEE Industrial Electronics Society, pp. 3064-3069, 2011.

[13] A.H. Etemadi, E.J. Davison, R. Iravani. A Decentralized Robust Control Strategy for Multi-DER Microgrids-Part I: Fundamental Concepts, IEEE Transactions on Power Delivery, Vol. 27 (issue 4): 1843-1853, October 2012.

[14] M. Babazadeh, H. Karimi, Robust decentralized control for islanded operation of a microgrid, IEEE Power and Energy Society General Meeting, pp. 1-8, 2011.
[15] A. Kahrobaeian, Y.A.I. Mohamed, Suppression of Interaction Dynamics in DG Converter-Based Microgrids Via Robust System-Oriented Control Approach, IEEE Transactions on Smart Grid, Vol. 3 (issue 4): 1800-1811, December 2012.

[16] H. Karimi, E.J. Davison, and R. Iravani, Multivariable Servomechanism Controller for Autonomous Operation of a Distributed Generation Unit: Design and Performance Evaluation, IEEE Transactions on Power Systems, Vol. 25 (issue 2): 853-865, May 2010.

[17] B. Bahrani, M. Saeedifard, A. Karimi, A. Rufer, A Multivariable Design Methodology for Voltage Control of a Single-DG-Unit Microgrid, IEEE Transactions on Industrial Informatics, Vol. 9 (issue 2): 589-599, May 2013.

[18] D.Q. Dang, Y.S. Choi, H.H. Choi, and J.W. Jung, Experimental Validation of a Fuzzy Adaptive Voltage Controller for ThreePhase PWM Inverter of a Standalone DG Unit, IEEE Transactions on Industrial Informatics, Vol. 11 (issue 3): 632-641, June 2015.

[19] H.M. Hasanien, M. Matar, A Fuzzy Logic Controller for Autonomous Operation of a Voltage Source Converter-Based Distributed Generation System, IEEE Transactions on Smart Grid, Vol. 6 (issue 1): 158-165, January 2015.

[20] P. March, M.C. Turner, Anti-windup compensator design for nonsalient permanent-magnet synchronous motor speed regulators, IEEE Trans. Industry Applications, Vol. 45 (issue 5): 1598-1609, September 2009.

[21] L.A. Zadeh, Outline of a new approach to the analysis of complex systems and decision processes, IEEE Transactions on Systems, Man, and Cybernetics, Vol. 3 (issue 1): 28-44, January 1973.

[22] E.H. Mamdani, S. Assilian, An experiment in linguistic synthesis with a fuzzy logic controller, International Journal of ManMachine Studies, Vol. 7 (issue 1): 1-13, 1975.

[23] K. Ogata, Modern control engineering, (Prentice Hall, $5^{\text {th }}$ Edition, 2010).

[24] S.D. Panjaitan, Development process for distributed automation systems based on elementary mechatronic functions (Shaker Verlag, 2008).

[25] Tephiruk, N., Hongesombut, K., Enhancement of Stabilizing Performance of a Microgrid Using Energy Storage System with Under Frequency Relay, (2016) International Review of Electrical Engineering (IREE), 11 (6), pp. 635-643.

[26] Elmahni, L., Bouhouch, L., Alaoui, R., Moudden, A., Modeling and Control of a Hybrid Microgrid by Multi-Agent System, (2015) International Review of Electrical Engineering (IREE), 10 (1), pp. 145-153.

[27] Brusco, G., Burgio, A., Menniti, D., Pinnarelli, A., Sorrentino, N., About the Effectiveness, the Electric Demand Profile Impact and the Imbalance Reduction of an Optimal Sized CHP Generator for an Agro-Industrial Microgrid Using Real Data, (2015) International Review of Electrical Engineering (IREE), 10 (3), pp. 362-369.

\section{Authors' information}

${ }^{1,2}$ Automation and Control Group, Department of Electrical Engineering, Tanjungpura University, Pontianak, Indonesia.

E-mail: seno.panjaitan@ee.untan.ac.id bomo.wibowo@ee.untan.ac.id

${ }^{3}$ High Voltage Engineering Group, Department of Electrical Engineering, Tanjungpura University, Pontianak, Indonesia. E-mail: rudi.kurnianto@ee.untan.ac.id

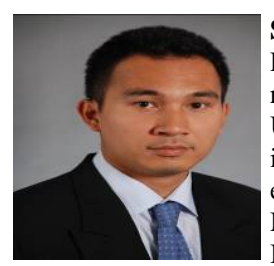

Seno Darmawan Panjaitan was born in Pontianak, Indonesia on July $16^{\text {th }}, 1975$. He received Bachelor of Engineering (S.T.) from Universitas Tanjungpura, Pontianak, Indonesia in 1997 with subject electrical engineering, especially in automation and control, and the Master of Engineering (M.T.) in 2001 from Institut Teknologi Bandung, Indonesia, in electrical engineering department with a specification in control and computer engineering. He achieved his doctoral degree in 2007 from Technical University of Kaiserslautern, Germany, in the department of 
electrical and computer engineering, especially in automation and control. He is now working as an Associate Professor in Department of Electrical Engineering, UNTAN, in the field of Automation and Control Engineering. His research interests are in automation, control, Intelligent systems, and smart energy systems. Dr.-Ing. Panjaitan is an IEEE member and joining several IEEE societies: IEEE Robotics and Automation, IEEE Control Systems, IEEE Power and Energy Society, and IEEE Smart Grid Community.

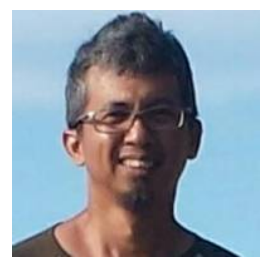

Bomo Wibowo Sanjaya was born in Pontianak, Indonesia on 1 April 1974. He received Bachelor's degree in control engineering from the electrical engineering department, Universitas Tanjungpura, Pontianak, Indonesia in 2008, and the Master's degree (2013) and doctoral degree (2014) in control engineering from the school of electrical engineering and informatics, Institut Teknologi Bandung, Indonesia. He is now a lecturer at the department of electrical engineering, Universitas Tanjungpura. His current research interests are in fuzzy logic, neural networks, control of nonlinear dynamical systems.

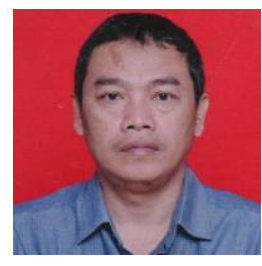

Rudi Kurnianto was born in Pontianak, Indonesia on 27 May 1967 . He received Bachelor degree in electrical engineering from Universitas Tanjungpura, Pontianak, Indonesia in 1994 and Master Degree in electrical engineering in 2001 from Institut Teknologi Bandung, Indonesia. He obtained Doctoral degree in High Voltage Engineering from the Toyohashi University of Technology, Japan in March 2008. He has been working as a lecturer in High Voltage Engineering group at Universitas Tanjungpura since January 1995, and now he is a Vice Dean of Academic Affairs in Engineering Faculty, Universitas Tanjungpura. His research interests are on high voltage engineering and power systems. Dr. Eng. Kurnianto is an IEEE member. 